\title{
Corpo, identidade e mediações culturais: o uso do cinema no ensino ${ }^{1}$
}

\author{
Body, identity and cultural mediations: the use of cinema in \\ teaching
}

\section{Jeimis Nogueira de Castro ${ }^{1}$; Eliane Portes Vargas²; Shirley Donizete Prado ${ }^{3}$; Francisco Romão Ferreira ${ }^{4}$}

1- Centro Federal de Educação Tecnológica Celso Suckow da Fonseca, Valença, Rio de Janeiro, Brasil jeimis.castro@cefet-ri.br - /ORCID 0000-0003-3468-5741

2- Fundação Oswaldo Cruz, Rio de Janeiro, Brasil - elianepvargas@ gmail.com - /ORCID 0000-0002-0236-3732

3- Universidade do Estado do Rio de Janeiro, Rio de Janeiro, Brasil - shirley.donizete.prado@gmail.com - /ORCID 00000001-5848-5766

4- Universidade do Estado do Rio de Janeiro, Rio de Janeiro, Brasil - chico.romao@ yahoo.com.br - /ORCID 0000-00034504-3621

\section{Recebido em 11/12/2018. Publicado em}

Palavras-chave:
Corpo.
Identidade.
Diferença.
Ensino.
Cinema.
Interculturalidade.

Keywords:

Body.

Identity.

Difference.

Teaching.

Movie theater.

Interculturality.
RESUMO: Este trabalho partiu da nossa vivência no contexto escolar e da literatura sobre os temas abordados: corpo, identidade e diferença. Elegemos o ensino de Educação Física como foco pelo fato de em muitos casos ser mais visível a busca de uma identidade fixa em estudantes por meio do controle dos corpos, mas os conteúdos abordados no texto não se restringem a essa área, podem ser utilizadas no ensino de Ciências ou em qualquer área do conhecimento que tenha interesse em promover discussões sobre essas questões. Assim sendo, o objetivo deste trabalho foi discutir de que maneira o ensino, com um direcionamento para aulas de Educação Física, pode colaborar no processo de construção das identidades em uma perspectiva intercultural a fim de estimular discussões sobre corpo, identidade e diferença em práticas pedagógicas. Para isso, adotamos o uso do cinema a fim de promovermos formas de resistência e rompimento de hierarquias e relações opressivas de poder para se chegar a uma possibilidade de ensino que contribua para a construção de uma sociedade mais equitativa, plural e humana.

\begin{abstract}
This work started from our experience in the school context and from literature on the topics covered: body, identity and difference. We chose Physical Education teaching as the focus because in many cases the search for a fixed identity in students through body control is more visible, but the contents covered in the text are not restricted to this area, they can be used in teaching of Sciences or in any area of knowledge that is interested in promoting discussions on these issues. Therefore, the objective of this work was to discuss how teaching, with a focus on Physical Education classes, can collaborate in the process of building identities in an intercultural perspective in order to stimulate discussions about body, identity and difference in pedagogical practices. To this end, we adopted the use of cinema in order to promote forms of resistance and the breaking of oppressive hierarchies and relations of power in order to arrive at a teaching possibility that contributes to the construction of a more equitable, plural and human society.
\end{abstract}

\footnotetext{
${ }^{1}$ Este texto consiste em uma versão ampliada e atualizada do trabalho intitulado: "CORPO, IDENTIDADE E DIFERENÇA: O USO DO CINEMA NO ENSINO DE EDUCAÇÃO FÍSICA”, apresentado no V Encontro Nacional de Ensino de Ciências da Saúde e do Ambiente em 2018.
} 


\section{INTRODUÇÃO}

O interesse por esta pesquisa ${ }^{2}$ surgiu da nossa experiência docente na educação básica. Ao observarmos discentes em movimento nas aulas de Educação Física, percebíamos em seus corpos algumas marcas culturais presentes na sociedade. Parecia-nos que esses corpos eram estimulados a se ajustarem de acordo com "padrões" comportamentais estabelecidos socialmente como "normais", corretos e que todos e todas precisam seguir. Percebíamos esses eventos como modelos normativos reproduzidos e reforçados por meio de todas as interações sociais no ambiente escolar.

Diante dessas observações, partimos, então, do pressuposto de que a sociedade conforma os corpos nos seus modos de andar, falar, gesticular, dançar e praticar exercícios físicos. Desde o início do Século XX essa relação é discutida na obra "As técnicas do corpo", escrito por Marcel Mauss (1950) em 1936. Cabe enfatizar que essa modelagem não se reduz às funções do corpo biológico ou ao desenvolvimento do organismo com vistas à melhoria da saúde ou da qualidade de vida no futuro. No dizer de Foucault (1999), ela opera também no âmbito dos valores morais e na docilização e submissão dos corpos às normas da cultura. Pierre Bourdieu (2008) também aponta para a construção de uma hexis corporal, uma forma como o corpo incorpora o habitus de classe do sujeito, que ali fica impregnado e é reproduzido de forma "espontânea", tornando os gestos "naturais", como se os modos de expressão corporal não fossem formas de expressão da cultura e dos códigos sociais.

O corpo do jovem escolar, portanto, não é apenas um organismo biológico a ser aperfeiçoado para a inserção na vida adulta ou no mundo do trabalho. É, com ênfase, o suporte de símbolos, códigos sociais, normas médicas, controles disciplinares e valores morais. O corpo é uma construção social e a escola, tendo a disciplina de Educação Física como foco principal, o lugar da socialização e do aprendizado de uma subjetividade que coloca o corpo como um organismo que precisa melhorar o seu desempenho para ter sucesso na vida social, elevar a sua qualidade de vida e ser preparado para o mundo do trabalho. $\mathrm{O}$ aprendizado do corpo operado no contexto escolar e nas disciplinas de Educação Física configura-se, então, em três dimensões, biológica, social e psíquica, em um processo que se constrói não apenas na natureza em seu corpo físico, mas também na cultura em suas dimensões simbólicas, subjetivas e sociais.

Dada a nossa inserção no ensino da Educação Física e com base na literatura sobre o tema (BOURDIEU, 2010; LOURO, 2014 e 2016; RODRIGUES, 2006; VARGAS, 2016),

\footnotetext{
${ }^{2}$ Pesquisa intitulada: "Identidade e gênero em cenas do cinema: um estudo sobre o ensino de Educação Física e a construção dos corpos no contexto escolar", como parte do doutoramento defendido no Programa de Pós-Graduação em Ensino em Biociências e Saúde no Istituto Oswaldo Cruz - Fundação Oswaldo Cruz, 2019.
} 
entendemos que a reprodução de modelos normativos é construída e lapidada nos gestos, falas, orientações, olhares, jogos, brincadeiras, ocupações de espaços e ações pedagógicas na escola. Muitas vezes, identificamos situações em que pessoas, por não se enquadrarem nas expectativas sociais de uma identidade considerada "padrão", são consideradas "anormais", “desviantes" e, por fim, conduzidas a se integrar ao grupo normativo visando à eliminação das diferenças que contrariam este modelo único de condutas. Dessa forma, o indivíduo marcado como diferente é pressionado a se adaptar às regras e às convenções, pois somente deste modo, passa a receber o mesmo tratamento que os demais socialmente aceitos. Essa marcação não está presente nos documentos oficiais. É uma determinação que aparece nas práticas cotidianas, rotineiras e comuns. São as práticas "educativas" que se dissimulam nos comentários jocosos, nas brincadeiras "inocentes" e nas repreensões habituais. São palavras, gestos e modos coercitivos que se apresentam naturalizados e, deste modo, reproduzem os marcadores sociais e as diferenças de gênero, raça, etnia, classe ou grupo social (LOURO, 2014).

No que tange ao ensino e à questão da diferença, como parte de um processo de construção das identidades sociais e culturais, ainda hoje, em muitas escolas, profissionais das áreas tanto de gestão pedagógica como de docência tendem a "ficar em silêncio" quanto a esta discussão. Falar do tema pode significar o despertar de preconceitos adormecidos e isso pode contribuir na reprodução das desigualdades sociais sendo os diferentes, continuamente ignorados, excluídos e discriminados do mesmo modo que seus problemas e demandas. Por outro lado, a atitude silenciosa pode também revelar uma dificuldade em conduzir adequadamente o tema, visto que o reconhecimento das diferenças e das identidades revelam os valores sociais envolvidos que nem sempre são considerados na formação profissional. Estudos como os Altman (2007 e 2015) apontam para estes aspectos.

Nesse contexto, procuramos problematizar o uso do cinema no ensino, tendo como objetivo, discutir de que maneira o ensino, com um direcionamento para aulas de Educação Física, pode colaborar no processo de construção das identidades em uma perspectiva intercultural a fim de estimular discussões sobre corpo, identidade e diferença em práticas pedagógicas. Essas práticas atualizam e disseminam no cotidiano escolar algumas narrativas de outros campos como o científico, o biomédico e o moral que, historicamente, vem sendo consolidados e naturalizados. As palavras de Sant'Anna (2001, p. 106) nos permitem perceber

[...] o quanto as definições hoje utilizadas para o corpo humano, sua saúde e seu bemestar, dentro e fora da Educação Física, possuem uma história densa, feita não apenas da resolução de problemas técnicos e científicos hoje considerados hilários, mas, igualmente, de receios e expectativas que, por vezes, não são mais os nossos. A partir delas é possível, enfim, compreender que esta importância extraordinária atribuída ao 
corpo em nossos dias tem razões antigas e inclui interesses que extrapolam o domínio das ginásticas, dos esportes e da saúde de cada um.

Para compreender este processo histórico e social de construção dos corpos e das identidades na Educação Física, Castro e Vargas (2017) realizaram levantamento bibliográfico na plataforma Scientific Electronic Library Online (SciELO) visando identificar as produções que abordam as questões relativas a corpo, gênero e ensino. Utilizaram o termo "Educação Física” como palavra-chave, encontrando 336 artigos em periódicos. Destes, 93 artigos eram oriundos de diversos campos, como Medicina, Nutrição, Pediatria, Psiquiatria, Pedagogia, Humanidades, entre outros e 243 artigos foram recuperados em periódicos específicos de Educação Física. A análise indicou que as abordagens relacionadas ao ensino escolar que têm foco no corpo como elemento de reflexão estiveram presentes em 03 artigos e aspectos relativos a gênero aparecem em 10 artigos. São números muito restritos que indicam a necessidade de realização de estudos mais aprofundados sobre esses temas.

Em outra pesquisa sobre publicações voltadas para essas temáticas, Devide et al. (2011), a partir de um mapeamento de aspectos relativos ao quadro teórico dos estudos de gênero na Educação Física no Brasil, identificaram as seguintes questões mais recorrentes: distribuição dos discentes por sexo em aulas mistas e coeducativas; fatores que contribuem para a exclusão nas aulas de Educação Física; resgate da memória de personagens ícones no desporto feminino esquecidas na história; desequilíbrio no espaço destinado à cobertura da participação das atletas nos eventos esportivos; número escasso de mulheres no comando e gerenciamento de equipes e instituições esportivas; e o desporto como uma área de reserva masculina. Essa pesquisa sugere alguns caminhos que ainda precisam ser ampliados e discutidos no ensino, entre os quais destacamos a participação da Educação Física e de esportes na construção das identidades, foco deste texto.

No que diz respeito ao uso do cinema no ensino a fim de problematizarmos reflexões sobre corpo, identidade e diferença, justifica-se a sua inclusão nas aulas pelo fato da linguagem cinematográfica nos apresentar diferentes corpos com suas gestualidades características de cada época, cultura ou grupo social. As imagens que aparecem na tela constituem um documento que traz à tona as representações sociais do corpo em diferentes contextos, épocas e situações, apresentando para os espectadores os conflitos culturais, étnicos e morais de diferentes grupos, construindo uma narrativa que pode ser utilizada em sala de aula como um "estudo de caso", como um modo de, ao discutirmos outra cultura, percebermos os códigos culturais e os valores morais da nossa cultura e dos nossos alunos e alunas. Por essa razão, utilizamos o cinema também como recurso de ensino, uma vez que a partir dos filmes podemos chamar a atenção para o controle dos gestos, dos corpos e dos 
sentidos de outra cultura.

Mediante a uma busca simples na internet na página do Google ${ }^{3}$, objetivando identificarmos os filmes mais utilizados e indicados para serem adotados no ensino de Educação Física, colocamos no buscador as palavras: educação física+filmes. Os filmes que aparecem nessa observação em sua grande maioria propiciam discussões ligadas aos esportes e a uma visão de corpo que precisa ser moldado, treinado e controlado, passando uma ideia simplista de uma perspectiva de educação redentora, de que com apenas disciplina, treinamento, dedicação e força de vontade é possível resolver todos os problemas sociais. A título de exemplo, a primeira página do resultado desse levantamento ${ }^{4}$ traz como indicação os filmes: Duelo de Titãs (2000); Menina de Ouro (2004); Coach Carter - Um Treino para a Vida (2005); Desafiando Gigantes (2006); Estrada para a Glória (2006); Para Sempre Vencedor (2008); Invictus (2009); Um Sonho Possível (2009); Senna (2010); e Sem Dor Sem Ganho (2013).

Os filmes citados acabam atraindo o público para uma abordagem de ensino, no que tange às discussões sobre corpo em aulas de Educação Física e de outras áreas, relacionada a práticas esportivas que transmitem por meio do treinamento uma concepção redentora para solucionarem os conflitos sociais e culturais. Por essa perspectiva, ser uma pessoa disciplinada, dedica e praticante de uma modalidade esportiva pode ser uma possibilidade de ascensão social. Diferente dessa abordagem, apontamos neste texto outras formas de uso do cinema para o ensino e para as aulas de Educação Física que não sejam restritas a olhar o corpo de uma forma mecânica e que precisa apenas ser treinado e controlado, mas que estimulem o diálogo, a reflexão, o olhar de empatia na relação com o "outro", o respeito às diferenças e a compreensão de que as culturas são construídas dialeticamente. Isto posto, trazemos neste texto, por meio de algumas cenas de dois filmes: Billy Elliot (2000) e Tomboy (2011), uma proposta de utilização do cinema e desses filmes em sala de aula, como uma forma de "estudo de caso" para problematizar questões referentes a mecanismos simbólicos de controle dos gestos e educações dos corpos que acabam sendo exercidos cotidianamente de modo a normalizar, fixar e estabilizar as identidades, como se tudo isso fosse algo natural. Isso porque olhar para o outro se torna uma boa forma de olhar para nós mesmos.

\section{O ENSINO DE EDUCAÇÃO FÍSICA E A PRODUÇÃO DA IDENTIDADE E DA DIFERENÇA}

\footnotetext{
${ }^{3}$ Realizamos o levantamento no dia 26/06/2019 na página <https://www.google.com/>.

${ }^{4}$ Disponível em: <https://dialogado.com.br/entretenimento/10-filmes-que-todo-estudante-de-educacao-fisica-precisaassistir/>. Acesso em: 26 jun. 2019.
} 
Segundo Louro (2010), muitas disciplinas do currículo escolar atuam na construção das identidades dos alunos e alunas por intermédio de discursos que se colocam de forma implícita, nos detalhes, em um comentário ou um olhar. Já na Educação Física, esse fenômeno parece, na maioria das vezes, manifestar-se de forma mais explícita e evidente durante as aulas, por meio de um constante exame corporal, da cobrança de determinadas posturas e da eficiência em gestos e formas de se expressar. Isso porque o corpo, além de ser o objeto privilegiado de intervenção desta área, traz na sua origem fortes influências de campos do saber, tais como Medicina e Biologia, bem como, características militares e esportivas (CASTELLANI FILHO, 2002). Este conjunto de saberes e características traz como principais preocupações de atuação na escola a manutenção da saúde, da higiene e da disciplina dos corpos. Tais referências orientam para a formação de cidadãos-soldados por meio do adestramento de seu comportamento no sentido de uma obediência cega, assim como para a constituição de futuros atletas em busca da conquista de medalhas para o país (GHIRALDELLI JÚNIOR, 1994).

Essas características favoreceram as condições de possibilidade para a construção de uma identidade fixa e estável a fim de que os indivíduos se encaixassem em um padrão social de comportamento. Assim, as diferenças tendem a ser apagadas, tornando-se até mesmo perigosas, pois perturbam os pensamentos e ações fortemente construídos e aceitos socialmente como verdades irrefutáveis de ordem e de norma. Silva (2014) diz que essa ideia de fixar uma identidade como sendo a norma corresponde a forma privilegiada de hierarquização das diferenças, pois esse processo de normalização que elege arbitrariamente um modelo único a ser seguido se articula a questões de poder que podem ocorrer de forma sutil.

A diferença, no que concerne à constituição das identidades, é muito abordada em debates que envolvem o ensino. De acordo com Nunes (2016), a diferença está sempre presente na escola. Aceita-se a sua presença, mas sua expressão é frágil. A qualquer sinal de perigo da estabilidade da identidade são mobilizados mecanismos para conter a sua força desestabilizadora. Isso ocorre porque

[...] a história da escola moderna pode ser caracterizada: pelo ajustamento de seus sujeitos às normas estabelecidas pela razão; pela transmissão de conhecimentos descobertos ou validados por meio de um método universal (científico); pela criação de singularidades que, primeiro, distingue os indivíduos; segundo, classifica os normais e os anormais, e, depois, seleciona e hierarquiza os sujeitos. A distinção dos aptos e dos inaptos era permeada com a expulsão de tudo que escapasse aos padrões e ameaçasse a ordem. Dada a condição na qual se entende que cada sujeito tem uma essência própria (Ser em si) e o Outro é a negação de si, no pensamento moderno, a diferença só pode ser vista como um desvio da norma (NUNES, 2016, p. 20). 
Para Silva (2014), identidade e diferença estão em uma relação de estreita dependência, sendo inseparáveis. As afirmações sobre diferença, para serem melhor compreendidas, trazem sempre junto as afirmações sobre identidade. Tomamos como exemplo a afirmação de sermos professores de Educação Física. Quando afirmamos esta identidade, ao mesmo tempo, estamos dizendo que não somos professores de Matemática, História, Português... Essas afirmações dependem de uma cadeia, na maioria das vezes oculta, de declarações negativas sobre (outras) identidades. Por isso, partimos do princípio de que a diferença relativa à identidade não pode ser naturalizada, cristalizada e nem essencializada. A identidade e a diferença precisam ser vistas como dados e fatos da vida em sociedade diante dos quais não convêm silenciar sob pena de excluir indivíduos da sociedade ao considerá-los desviantes (BECKER, 2008). Identidade e diferença estão sujeitas a vetores de força por serem impostas e disputadas em relações conflituosas e hierárquicas, sendo o resultado de um processo de produção simbólica e discursiva. Dessa forma, afirmar uma identidade significa demarcar fronteiras, fazer distinções entre aquele que fica dentro e o outro que fica de fora. Assim, a identidade expressa uma separação entre "nós" e os "outros".

\footnotetext{
Essa demarcação de fronteiras, essa separação e distinção, supõem e, ao mesmo tempo, afirmam e reafirmam relações de poder. "Nós" e "eles" não são, neste caso, simples distinções gramaticais. Os pronomes "nós" e "eles" não são aqui, simples categorias gramaticais, mas evidentes indicadores de posição-de-sujeito fortemente marcadas por relações de poder (SILVA, 2014, p. 82).
}

Essa divisão social entre "nós" e os "outros" significa classificar e hierarquizar por meio de estruturas binárias, como normal/anormal, homem/mulher, bonito/feio, homossexual/heterossexual, entre outras. Essas classificações são sempre feitas a partir do ponto de vista da identidade e quem tem o privilégio de classificar, também tem o privilégio de determinar diferentes valores aos grupos que foram classificados. Por isso, é necessário questionar as relações de poder, problematizando esses binarismos produzidos na construção da identidade e da diferença.

Para levar essas problematizações ao campo do ensino e para aulas de Educação Física, de Ciências ou de qualquer área do conhecimento que tenha vínculo com o tema, podemos recorrer aos trabalhos de Candau (2011, 2013 e 2014), quando coloca a perspectiva da educação intercultural, que almeja promover um ensino para o reconhecimento do "outro", estimulando o constante diálogo com os diferentes grupos sociais e culturais. Atuando no sentido da negociação cultural, que não procura apagar e esconder as diferenças, mas reconhecer e dirigir o olhar para os conflitos que surgem pelas assimetrias nas relações de 
poder entre os diferentes grupos sociais e culturais. Essas proposições orientam para a construção de esforços comuns em que as diferenças sejam incluídas e dialeticamente discutidas.

Há, evidentemente, desafios a serem enfrentados em uma proposta de ensino intercultural: o primeiro busca a desconstrução, mergulhando nos preconceitos e discriminações que estão presentes de forma sutil nas relações sociais; o segundo questiona o caráter monocultural e o etnocentrismo presentes na escola, nas políticas e currículos escolares, para desestabilizar a "neutralidade" dos conhecimentos, valores e práticas no ensino escolar; o terceiro desafio é trabalhar com um conceito dinâmico e histórico de cultura, visando possibilitar práticas integradoras das raízes históricas com as novas configurações, fugindo de percepções fechadas e da cultura "pura", "autêntica" e "genuína", com essência pré-estabelecida; o quarto e último desafio diz respeito à promoção de experiências de interações sistemáticas com os "outros”, para repensar nossa visão de mundo, experimentando uma intensa interação com diferentes modos de se viver e se expressar.

Levando esses desafios para o ensino, elegemos o cinema para abordar a ética da compreensão humana (MORIN, 2009) e a relação das imagens fílmicas que se estabelecem entre realidade e representações (AUMONT, 1993).

\section{O CINEMA E AS PRÁTICAS DE ENSINO: UMA RELAÇÃO POSSÍVEL}

Como já discutimos, o ensino de Educação Física teve fortes marcas de busca por uma fixação da identidade de estudantes, padronizando os comportamentos, adestrando os corpos e estimulando processos de uniformização e homogeneização, invisibilizando, negando e silenciando as diferenças. Em face desse cenário e tendo por horizonte um ensino intercultural, adotamos o uso do cinema no ambiente escolar a fim de estimularmos reflexões sobre processos de construção de identidades plurais, abertas, dinâmicas e, sobretudo, mais complexas do que as construções binárias que orientam nossos esquemas de percepção. Estão em foco aqui a valorização das histórias de vida dos estudantes, bem como as tentativas de favorecer a troca, o intercâmbio e o reconhecimento mútuo na escola. Esta proposta busca questionar quem incluímos como "nós" e quem elegemos como os "outros" e, da mesma forma, indagar como e por que caracterizamos esses dois grupos de formas distintas.

Por tudo isso, podemos dizer que existe uma relação possível entre o uso do cinema e as práticas de ensino. Os filmes nos proporcionam viagens pela história e pelos continentes, fazendo com que o grupo que se intitula como "nós" possa se colocar no lugar do grupo considerado como "outros". O cinema nos leva para dentro de guerras e de conjunturas de 
paz. Mostra-nos as características da condição humana, mergulhando na "singularidade de destinos individuais localizados no tempo e no espaço" (MORIN, 2009, p. 44). Ensina-nos as maiores lições que um ser humano pode vivenciar, "a compaixão pelo sofrimento de todos os humilhados e a verdadeira compreensão" (MORIN, 2009, p. 51). Por meio dessas lições, os filmes podem despertar a recusa ao ódio e à exclusão tão presentes na construção das identidades, principalmente, quando associadas às diferenças que se expressam a todo momento na escola.

Partindo dessa relação, buscamos apresentar uma proposta intercultural, que pode ser usada tanto no ensino de Educação Física como no de Ciências, a partir dos filmes: Billy Elliot (2000) e Tomboy (2011). Tendo como base os trabalhos de Castro e Vargas (2016) e Castro, Vargas e Ferreira (2017), orientamo-nos no sentido de promover discussões sobre corpo, identidade e diferença na escola utilizando uma pedagogia das imagens (FISHER, 2014). Usamos o cinema no ensino de modo a estimular estudantes e docentes a desacomodarem-se, desviando seus olhares daquilo que já é esperado, como um clichê ou uma fórmula já conhecida. Dessa forma, após assistirem aos dois filmes, os espectadores têm oportunidade, por meio de reflexões e debates, de colocar suas perspectivas de vida social e de mundo em exame a partir, tanto da imagem cinematográfica, quanto da visão de si próprios.

Os espectadores podem relatar brevemente o que mais chamou a sua atenção no filme, as cenas que surpreenderam ou que causaram estranhamentos. Assim, já é possível promover o reconhecimento do "outro" e o diálogo entre os diferentes grupos sociais e culturais, favorecendo uma visão dinâmica, contextualizada e plural das identidades. Uma questão igualmente importante que aparece quando analisamos filmes em sala de aula é a tentativa de compreender como a narrativa foi construída. Mais do que discutir o que os atores e atrizes fazem em cena, é tentar perceber como e porque fizeram daquela forma, que valores, interesses ou ideias estavam por trás daquela sequência para que fosse construída daquela maneira e não de outra. Fatores como a valorização e o detalhamento dos diálogos, dos sentidos presentes nas falas dos personagens, nos modos de enquadramento, no clima da cena específica, na atmosfera do filme ou na percepção das emoções que a película provoca nos espectadores são relevantes. Tudo isso ajuda o aluno e a aluna a perceberem que todos os discursos são construídos, os discursos dos atores e atrizes e os nossos também, afinal, também representamos um papel social e nossas falas também fazem parte de um jogo discursivo que reproduz o jogo social. Também somos atores encenando papéis que às vezes nos aprisionam.

Os dois filmes propiciam caminhos para reflexões importantes sobre corporeidade. 
Em Tomboy (2011), há a passagem em que Michael e Lisa observam os garotos jogando futebol (cena 20"37”). Em outro momento, diante do espelho, Michael treina os movimentos observados durante o jogo (cena 22'53”), olha suas estruturas corporais e repete alguns movimentos observados. Mais adiante, durante o jogo de futebol com os amigos, Michael exercita modos de tirar a camisa e de cuspir no chão (cena 24'54”). Já no filme Billy Elliot (2000), há o momento em que Billy observa o pai e o irmão discutindo (cena 44'24”) o que inclui atos violentos; mais tarde, o menino age da mesma forma agressiva em um momento de confronto com sua professora de balé (cena 46’07'). Billy ainda reproduz esse modelo truculento quando, muito nervoso, de forma automática, dá um soco no garoto que tenta consolá-lo após o seu teste de seleção para a escola de balé (cena 01²6’09”).

Por meio dessas cenas descritas, é possível encaminhar inúmeras discussões de caráter pedagógico sobre significados do corpo na sociedade contemporânea e sua relação com saberes disciplinares. Podemos propor aos espectadores diversos questionamentos: como o filme retrata o corpo? Como esse corpo aprende a ser assim? O que a observação dos corpos das pessoas nos mostra? Como os personagens incorporam novas formas corpóreas de se expressar? Como isso ocorre? Como os personagens colocam em prática esse aprendizado do corpo? Qual a relação das imagens produzidas com a realidade cotidiana experimentada na vivência escolar?

No filme Tomboy (2011), questões relativas à identidade e diferença pode ser exploradas por meio do encontro de Laure com Lisa em que, ao ser perguntada sobre seu nome, Laure se apresenta como Michael (cena 08'44”). Já no filme Billy Elliot (2000), é possível trazer a conversa entre Billy e Debbie sobre o balé. Billy mesmo gostando de participar da aula, rejeita a atividade dizendo que isso é para "bichas" (cena 14'56"). Pode-se estimular a troca de ideias a partir de um amplo leque de questões: que personagens chamam a sua atenção? Por quê? Em quais cenas podem remeter a aspectos relativos à identidade? Por quê? Como as identidades foram construídas no filme? Quem está envolvido nesta construção? E na sociedade, como se dá essa construção? Como as identidades se manifestam nos diferentes contextos?

Os dois filmes aqui em tela podem favorecer muitas abordagens sobre o tema. Estes exemplos acima apresentados são apenas algumas possibilidades direcionadas para o ensino, e mais especificamente, ligado ao ensino de Educação Física. São, ademais, questões que também podem ser abordadas no ensino de Ciências, especialmente, naquele que se ocupa das biociências e da saúde, onde há uma predominância da perceptiva biomédica em suas abordagens. Vale destacar a convocação de docentes que atuam no ensino de Biologia nas escolas para o tratamento destas temáticas como tema transversal, o que envolve aspectos 
relativos à saúde e prevenção de doenças sexualmente transmissíveis (DE CICCO; VARGAS, 2012). Numa perspectiva mais ampliada, consideramos que os elementos aqui tratados podem servir de referência para qualquer prática ou pesquisa em ensino interessada em estimular uma abordagem intercultural visando à formação cidadã e à realização humana.

Buscamos, portanto, contribuir para este debate problematizando, no âmbito do ensino de Educação Física, as diferenças presentes ao longo da história entre os diversos grupos sociais, visando compreender como as culturas operam um constante processo de construção, desestabilização e reconstrução das identidades que necessitamos (re)conhecer. Este processo permeia o conjunto de ações de natureza educativa e de ensino, na maneira como nós o concebemos (VARGAS, 2016), seja formal ou não-formal, no contexto da escola.

O ensino de Educação Física não se resume ao treinamento, ao condicionamento físico e à preparação dos corpos na perspectiva biológica. Diferentemente, vai além dos conteúdos formais, extrapola e ingressa no território do simbólico, da reprodução do modus operandi da cultura com seus valores éticos, estéticos e morais. Segundo a Professora Yara Maria de Carvalho (2001, p. 99), tradicionalmente,

[...] a Educação física tem-se preocupado com o corpo, com a aparência, com a forma, com o rendimento, com a avaliação, com a moral, não com poucos temas. Mas ainda que seja com o movimento do corpo humano há necessidade de ir além, de não se fixar no "fazer" do movimento e da cultura corporal. Há que se compreender a lógica que sustenta o sentido do pensamento, das ações e das funções que se traduzem também no que se pensa e as faz com o intuito de ir ao encontro do homem e não contra ele.

\section{CONSIDERAÇÕES FINAIS}

Partindo da nossa inserção no contexto escolar e da literatura sobre o tema, procuramos trazer neste trabalho aspectos relativos ao uso do cinema no ensino, tendo como objetivo discutir de que maneira o ensino, com um direcionamento para aulas de Educação Física, pode colaborar no processo de construção das identidades em uma perspectiva intercultural a fim de estimular discussões sobre corpo, identidade e diferença em práticas pedagógicas, mostrando que as discussões sobre esses temas também podem ser adotadas no ensino de Ciências ou em outras áreas do conhecimento.

Nessa perspectiva intercultural, indicamos que o cinema pode ajudar as pessoas na construção do conhecimento sobre o mundo em que vivem, colocando à vista diversas formas de interação social entre "nós e os "outros" e possibilitando que os caracteres existenciais e subjetivos que nos constituem como sujeitos históricos se tornem sensíveis. Para isso, consideramos que os filmes Billy Elliot (2000) e Tomboy (2011) podem ser usados para 
estimular reflexões a partir dos personagens principais em momentos de sociabilidade para questões sobre corporeidade e respeito às diferenças identitárias.

A motivação deste estudo se deu por observações e inquietações a respeito da forma como os corpos dos alunos e alunas eram educados e conduzidos a um modelo de comportamento normativo, bem como a dificuldade das escolas em problematizar aspectos referentes à diferença, principalmente em discussões sobre essas temáticas. Outra questão que nos motivou foi o olhar que muitas práticas pedagógicas adotam em relação ao corpo por um viés exclusivamente biológico, como se o corpo já estivesse predeterminado a apenas responder estímulos para que ele atinja as fases de amadurecimento e chegue à vida adulta com um direcionamento para o mundo do trabalho. Por essa razão, apontamos no decorrer das reflexões aqui realizadas que o corpo não seja vinculado exclusivamente aos aspectos biológicos, mas que seja compreendido também a partir de uma conexão entre a natureza e a cultura. Desse jeito, entendemos o corpo como um documento vivo, dado que ele carrega em todas as suas estruturas a memória de um tempo e a história da sociedade. Então, estudar o corpo por essa perspectiva nos ajuda a entender o passado, a compreender o presente e a pensar o futuro.

Diante do nosso objetivo, abordamos sobre como o corpo fica em evidência nas aulas de Educação Física e possibilita que as diferenças também fiquem mais explícitas, por consequência, o controle sobre esses corpos e a fixação de um modelo de identidade acaba sendo feito de uma forma mais rígida. Também discutimos a respeito da estreita relação de dependência entre identidade e diferença, mostrando que essa dependência fica sujeita a vetores de poder e são disputadas por relações conflituosas e hierárquicas que geram divisões sociais entre "nós" e os "outros". Por essa razão, adotamos uma perspectiva de ensino fundamentada pela interculturalidade e pelo cinema de modo que as identidades sejam consideradas, reconhecidas e valorizados por uma abordagem plural, aberta e dinâmica, que busca uma prática pedagógica que promova uma negociação cultural, reconhecendo e enfrentando os conflitos que surgem pelas assimetrias das relações de poder entre os diferentes grupos sociais e culturais, promovendo um ambiente de ensino em que as diferenças sejam incluídas e discutidas dialeticamente.

Apresentamos um levantamento de artigos publicados em periódicos nacionais a fim de conhecermos os focos de interesse da área Educação Física e, mais detalhadamente, as produções ligadas a corpo e gênero que atuam na construção das identidades dos alunos e alunas na escola formal. Por intermédio desse levantamento, constatamos que os focos dos artigos encontrados foram, respectivamente, em problematizações de cunho pedagógico e social, o que mostra uma tentativa de ampliação de uma visão biologicista, médica, militarista 
e esportiva da área. Em relação aos artigos que discutiam corpo e gênero na escola influenciando na construção identitária, o número encontrado foi pequeno, demonstrando que essas questões são pouco examinadas e precisam de mais atenção, visto que interferem na construção social dos sujeitos.

Em vista das nossas reflexões e com o apoio da literatura, podemos perceber que a construção das identidades nos corpos dos alunos e alunas em muitas escolas e em aulas de Educação Física ocorre de forma simplista e redutora, dado que essa construção acaba se constituindo basicamente pelo aprendizado de papéis sociais que moldam os comportamentos, as roupas e as formas de se vestir e se relacionar, reforçando as marcas da sociedade vigente. Por conseguinte, quando não há problematizações na escola em relação aos temas explorados - corpo, identidade e gênero - o ensino pode atuar de forma a reproduzir discriminações e hierarquizações as entendendo como algo dado, natural e essencializado, legitimando assim as assimetrias. Esse ensino pode fazer com que a socialização de alunos e alunas se restrinja ao direcionamento sobre o que cada um pode e não pode fazer, separando e informando o "lugar" dos meninos e das meninas, apontando os modelos que devem seguir, formando identidades e corpos escolarizados.

Almejamos que este texto possa contribuir para a ampliação de propostas interculturais, para a utilização do cinema no ensino e para favorecer a sensibilização e discussões de temas ligados ao corpo, à identidade e à diferença, bem como para a produção de formas de resistência e rompimento de hierarquias e de relações opressivas de poder. Tudo isso, visando à construção de uma sociedade mais equitativa, plural e humana, promovendo um ensino para o reconhecimento do "outro" e para o diálogo entre os diferentes grupos sociais e culturais.

\section{REFERÊNCIAS}

ALtMANN, H. Pedagogias da sexualidade e do gênero na educação física escolar. Motriz: Revista de Educação Física (Online), v. 13, p. S65, 2007.

Educação Física Escolar: relações de gênero em jogo. São Paulo: Cortez, 2015.

AUMONT, J. A Imagem. Campinas, SP: Papirus, 1993.

BECKER, H. S. Outsiders: estudos de sociologia do desvio. Rio de Janeiro: Zahar, 2008.

BILLY ELLIOT. Direção: Stephen Daldry. Produção: Greg Brenman. Roteiro: Lee Hall.

Fotografia: Brian Tufano. Música: Stephen Warbeck. Reino Unido: BBC Films; StudioCanal;

Working Title Films, 2000. 1 bobina cinematográfica (110MIN), Color. son., color., 35mm.

Disponível em: <https://www.cineclick.com.br/billy-elliot>. Acesso em: 16 fev. 2019. 
BOURDIEU, P. A dominação masculina. 9. ed. Tradução: Helena Kühner. Rio de Janeiro:

Bertrand Brasil, 2010.

A distinção. Crítica social do julgamento. São Paulo: EDUSP, 2008.

CANDAU, V. M. Educação em direitos humanos e diferenças culturais: questões e buscas. In.:

CANDAU, V. M. (Org.). Diferenças Culturais e Educação. Construindo Caminhos. Rio de Janeiro: 7Letras, 2011.

Multiculturalismo e educação: desafios para a prática pedagógica. In.:

CARVALHO, Y.M. Educação Física e Filosofia. In: CARVALHO,Y.M. \& RUBIO, K. Educação

Física e Ciências Humanas. Campinas: HUCITEC, 2001.

CASTRO, Jeimis Nogueira de; VARGAS, Eliane Portes. Corpos generificados à mesa e na escola em cenas do filme Tomboy: entre desejos e prescrições. In: FERREIRA, Francisco Romão et al.

(Org.). Cinema e comensalidade. Curitiba: CRV, 2016, p. 169- 185.

Uma análise das publicações na área de educação física: dos movimentos corporais às questões de gênero na escola. $8^{\circ}$ Congresso Norte Paranaense de Educação Física Escolar, ANAIS... Londrina, Paraná, 2017. Disponível em:

$<$ http://www.uel.br/eventos/conpef/portal/pages/arquivos/ANAIS\%20CONPEF\%202017/uma\%20analise\%2 0130965-19985.doc.pdf>. Acesso 14 jan. 2018.

CASTRO, Jeimis Nogueira de; VARGAS, Eliane Portes; FERREIRA, Francisco Romão.

Comensalidade e identidade social: a construção social da masculinidade no filme Billy Elliot. In:

VARGAS, E. P et al. (Org.). Cinema e Comensalidade 2. Curitiba: CRV, 2017, p. 73-94.

MOREIRA, A. F.; CANDAU, V. M. (Org.). Multiculturalismo: diferenças culturais e práticas pedagógicas. 10. ed. Petrópolis: Vozes, 2013.

Educação intercultural: entre afirmações e desafios. In.: MOREIRA, A. F.; CANDAU, V.

M. (Org.). Currículos, disciplinas escolares e culturas. 10. ed. Petrópolis: Vozes, 2014.

CASTELlani FILHO, L. Política educacional e Educação Física. Campinas: Autores

Associados, 2002.

De CICCO, R. R.; VARGAS, Eliane Portes. As Doenças Sexualmente Transmissíveis em livros didáticos de biologia: aportes para o ensino de ciências. Revista Electrónica de Investigación en Educación en Ciencias (En línea), v. 7, p. 10-21, 2012.

DEVIDE, F. P. et al. Estudos de gênero na Educação Física Brasileira. Motriz, Rio Claro, v.17 n.1 p.93-103, jan./mar. 2011.

FISCHER, R. M. B. Cinema e juventude: uma discussão sobre ética das imagens. Educação. v. 37, n. 1, p. 42-51, jan./abr., 2014.

FOUCAULT, M. Vigiar e Punir. Petrópolis: Vozes, 1999. 
GHIRALDELLI JÚNIOR, P. Educação Física progressista. A pedagogia crítico-social dos conteúdos e a Educação Física brasileira. São Paulo: Loyola, 1994.

LOURO, G. L. Gênero, sexualidade e educação: uma perspectiva pós-estruturalista. 11. ed. Petrópolis, RJ: Vozes, 2014.

Um corpo estranho - Ensaios sobre sexualidade e teoria queer. 2. ed. Belo Horizonte:

Autêntica, 2016.

MAUSS, M. Les techniques du corps. Paris: PUF, 1950.

MORIN, E. A cabeça bem-feita: repensar a reforma, reformar o pensamento. Tradução: Eloá Jacobina. 16. ed., Rio de Janeiro: Bertrand Brasil, 2009.

NUNES, M. L. F. Afinal, o que queremos dizer com a expressão "diferença"? In.: NEIRA, M. G.;

NUNES, M. L. F. (Org.). Educação Física Cultural: por uma pedagogia da(s) diferença(s).

Curitiba: CRV, 2016.

RODRIGUES, J. C. Tabu do corpo. 7. ed., ver. Rio de Janeiro: FIOCRUZ, 2006.

SANT’ ANNA, D. B. Educação Física e História. In.: CARVALHO, Y. M. \& RUBIO, K. Educação Física e Ciências Humanas. Campinas: HUCITEC, 2001.

SILVA, T. T. A produção social da identidade e da diferença. In.: SILVA, T. T. (Org.). Identidade e diferença: a perspectiva dos estudos culturais. Petrópolis, RJ: Vozes, 2014. p.73-102.

TOMBOY. Direção: Céline Sciamma. Produção: Bénédicte Couvreur. Roteiro: Céline Sciamma. Fotografia: Crystel Fournier. Música: Jean-Baptiste de Laubier. França: Arte / Cofinova 6, Arte France, arte France Cinéma, Canal+, Centre National de la Cinématographie (CNC), Films Distribution, Hold Up Films, Lilies Films, Région Ile-de-France, 2011. 1 bobina cinematográfica (82MIN), Color. son., color., 35mm. Disponível em: Disponível em:

$<$ https://www.cineclick.com.br/tomboy>. Acesso em: 16 fev. 2019.

VARGAS, Eliane Portes. A favor da diversidade: ensaio sobre saberes nas pesquisas em saúde focalizando o corpo. In: PRADO, Shirley Donizete et al. Estudos socioculturais em alimentação e saúde: saberes em rede. Rio de Janeiro: EdUERJ, 2016, p 17-32. 